\title{
A Case Study of Intercultural Sensitivity of Junior School Students in an International School
}

\author{
Xinjie Luo ${ }^{1}$, Chubai Liu ${ }^{1} \&$ Qingsheng $\mathrm{Lu}^{1}$ \\ ${ }^{1}$ Foreign Languages College, Jiangxi Normal University, China \\ Correspondence: Qingsheng Lu, Foreign Languages College, Jiangxi Normal University, Yaohu Campus, 99 \\ Ziyang road, Nanchang, Jiangxi, 330022, China.
}

Received: November 3, 2021

Accepted: December 13, 2021

Online Published: December 23, 2021

doi: 10.5539/elt.v15n1p69

URL: https://doi.org/10.5539/elt.v15n1p69

\begin{abstract}
The process of internationalization requires people to have higher intercultural communicative competence, which refers to a person's ability to successfully communicate in different cultural environments. It consists of cognition, emotion, and behavior. The study of intercultural sensitivity actually focuses on the emotional factor in intercultural communication competence. Based on the concept of intercultural sensitivity and English teaching practice, this article intends to contribute a little to the intercultural communication teaching and relevant study by analyzing the current level of intercultural sensitivity of junior high school students and interviewing English teachers about the implementation of intercultural teaching strategies.
\end{abstract}

Keywords: intercultural communication, intercultural sensitivity, instructional strategy

\section{Introduction}

In the context of globalization, more and more local enterprises will participate in the international division of labor and international cooperation. The increasing frequency of intercultural exchanges puts forward higher requirements on school English teaching. On the basis of improving students' English proficiency, foreign language teaching needs to cultivate students' intercultural communication ability to deal with the influence of various emotional factors in intercultural communication. Intercultural sensitivity is the essential factor of intercultural communication. Only by holding the correct cognition and emotional orientation to cultural shock can we effectively respond to cultural shock and smoothly carry out intercultural communication.

\section{Literature Review}

\subsection{The Definitions of Intercultural Communication Skills}

Spitzberg (1994) believed that intercultural communicative competence is the ability to successfully achieve intercultural communicative goals. This ability is composed of three factors: knowledge, motivation, and skills, none of which is indispensable. He emphasized the specificity of communication situations and the appropriateness and effectiveness of communication behaviors, emphasizing that intercultural communication requires sufficient cross-cultural knowledge, positive motivation and effective communication skills.

Kim' (2005) defined intercultural communicative competence as the individual inherent ability to change one's psychological characteristics and structure to adapt to the requirements of the environment, and to be able to deal with key issues in intercultural communication. He argued that intercultural communicative competence is composed of cognitive ability, emotional ability and behavioral ability, which are interrelated and influence each other.

Based on reality, this study believes that intercultural communicative competence is the use of verbal and non-verbal means to achieve appropriate communication in a intercultural environment, which makes people be more objective and open to their own and other ethnic cultures, thus to be able to adjust minds and behaviors to adapt to other cultures and environments.

\subsection{The Definitions of Intercultural Sensitivity}

The concept of intercultural sensitivity began with the discussion proposed by Bronfenbrenner, Harding \& Gallwey (1958), which consists of the sensitivity of both national culture and other cultures. They believe that 
"interpersonal sensitivity is the ability to discover how other people's behavior, knowledge, and feelings are different from ours."

Bhawuk \& Brislin (1992) described intercultural sensitivity as "a sensitivity to the importance of cultural differences and the views of people in other cultures".

Chen \& Starosta (2000) defined intercultural sensitivity at the emotional level and regarded it as the subjective willingness of people to inspire their own understanding, appreciation, and acceptance of cultural differences.

This study prefers Brislin, Chen \& Starosta's definition of intercultural sensitivity. The author believes that people with high intercultural sensitivity are more inclined to discover the similarities and differences between other cultures and their own culture. Secondly, people with high intercultural sensitivity can adjust themselves to accept, understand, respect, and appreciate cultural differences. Finally, people with high intercultural sensitivity could manage cultural differences and similarities flexibly to cultivate intercultural communication skills and problem solving ability.

\subsection{The Definitions of Teaching Strategy}

Shi Junqing (1995) believed that as teaching concepts or principles, teaching strategies are reflected in teaching methods and teaching models.

In Educational Psychology (1997), Zhang Dajun defined the teaching strategy as the teaching plan and the teaching implementation measures formulated in a specific teaching situation to complete the teaching goal and adapt to the cognitive needs of students.

Teaching strategy is the overall planning and controlling of teaching implementation, rather than an abstract teaching principle. It has specific and clear content and it is operable (Shi Junqing, 2007).

\subsection{Overseas Related Research}

Bhawuk \& Brislin took individualism and collectivism as the breakthrough point to explain the intercultural sensitivity. In 1992, they jointly proposed the Intercultural Sensitivity Inventor (ICSI). However, the reliability of this scale has been questioned by scholars.

Chen \& Starosta (1996) believed that intercultural communication competence should include cognitive, affective and behavioral competence in the process of intercultural communication, which respectively refer to intercultural awareness and intercultural sensitivity (Chen \& Starosta, 1996). They believed that intercultural sensitivity consists of six factors: self-esteem, self-monitoring, open-mindedness, empathy, interaction involvement and non-judgment (Chen \& Starosta, 2000). On this basis, Chen and Starosta first designed 73 scales to measure six characteristics of intercultural sensitivity. They collected data from students studying in the United States. By using factor analysis method, they eliminated the factor loading value less than 0.5 of 49 questions, kept 24 questions and proposed the Intercultural Sensitivity Scale (ISS). The reliability (Cronbach's $\alpha=0.88$ ) of the new scale was obtained when it was tested again on the students they chose before. It was proved to have high reliability and validity. In 2000, Chen and Starosta published the new intercultural sensitivity scale in Human Communication. This scale is one of the most widely used scales in the world to measure intercultural sensitivity. It contained 24 items and 5 points, and measured five variables at different levels of intercultural sensitivity, namely, interaction engagement, respect for cultural differences, interaction confidence, interaction enjoyment and interaction attentiveness.

Later in 2002, Fritz, Mollenberg and Chen used ISS to evaluate 541 German students, and the research results proved that this scale is effective, reliable and applicable to various cultures.

In 2015, Ali of Iran used ISS scale to measure the cross-cultural sensitivity of 60 English learners of different ages from different industries. The results showed that the scale has high reliability and validity and can be used by people with different cultural backgrounds. However, the concept of internal factors of cross-cultural sensitivity in the scale needs to be improved.

\subsection{Domestic Related Research}

In April 1982, Hu Wenzhong published an article named Cultural Differences and Teaching of Foreign Languages, in which he argued that the relationships between language and culture, between linguistic competence and communicative competence, between foreign language teaching and various subjects should be clarified. He emphasized that language can't exist without culture and that language is a mirror of national culture and customs. Due to the wide range of cultural differences, the beginners may pay attention to the major differences and then go deep into details. Finally, Mr. Hu proposed seven important teaching strategies from the perspective of sociolinguistics. 
Zhou Xingying, Peng Xuemin (2007) summarized their previous empirical studies in their Influence of Cultural Learning on Intercultural Sensitivity. They adopted Chen and Starosta's intercultural sensitivity scale to explore whether cultural learning can improve students' intercultural sensitivity by evaluating the level of intercultural sensitivity of college students. The research results show that students have significantly improved their interaction engagement and respect for cultural differences. However, the observation period of cultural teaching in this study is comparatively short, and students' self-evaluation is high, so the research results are a little less objective.

In 2012, Yu Weiqi used Chen \& Starosta's intercultural sensitivity scale to conduct a survey of 270 international students in China on intercultural sensitivity and effectiveness of intercultural communication. It has been proved that the development of intercultural sensitivity and effectiveness of intercultural communication is uneven among international students from different countries and regions. Students from Europe and the United States performed better than those from Asia. The research also showed that the five variables of intercultural sensitivity are closely related, and intercultural sensitivity and intercultural communication effectiveness may influence each other.

In 2014, Qu Nini and Dou Qin conducted Chen \& Starosta intercultural sensitivity scale and self-designed cross-cultural communicative competence test questionnaire respectively on foreign language learners (including teachers, students, staffs) of the Northwest Agriculture and Forestry University of Science and Technology, the results showed that the relationship between the intercultural sensitivity and intercultural communicative competence is more close. Among the five factors of cross-cultural sensitivity, foreign language learners show the strongest level of interaction engagement and the weakest interaction enjoyment. Foreign language learners' interaction engagement and confidence are higher than interaction attentiveness, interaction enjoyment and respect for cultural differences, while their interaction engagement is higher than the other four factors.

Even domestic study on intercultural sensitivity started later than abroad, it has gradually enriched since the 21 st century. These works mainly focus on adults such as foreign students, college students, school staff, and multinational corporate employees, but lack the research on younger junior high school students. What's more, the research on teaching strategies has reached a certain depth in theory, whether it is frame construction or essential definition, and has been very detailed and specific in guiding practice. However, the overall attention focused on the understanding and mastery of cultural knowledge, but the research on teaching strategies to cultivate and improve intercultural sensitivity from students' early age has been neglected. In view of this, based on the concept of intercultural sensitivity, this study investigated a total of 89 foreign junior high school students in China and 18 TCSL teachers of an international school in Nanchang. Using the combination of questionnaire and interview research method, the intercultural sensitivity of foreign junior high school students in China and relevant teaching strategies were researched. It is hoped that this study can play a role in attracting more scholars and teachers to pay attention to this field.

\section{Methodology}

\subsection{Research Question}

1) What is the status quo of the overall intercultural sensitivity of junior high school students in an international school?

2) What is the relationship between internal factors of intercultural sensitivity?

\subsection{Participants}

The subjects of this study are foreign junior middle school students in the middle school of an international school in Nanchang. There are 89 students in total, 33 in grade one, 24 in grade two and 32 in Grade three. Totally 18 teachers who teach Chinese in this school were interviewed.

The author selected junior high school students and teachers who teach Chinese from an international school in Nanchang as the subjects for the questionnaire and interview. The international school's students come from all over the world, and its Chinese classes adopt layered teaching according to different levels. The common language of instruction for the junior classes (beginners) is English, so teachers basically teach Chinese in English. Middle-level classes can communicate partly in Chinese, but when they encounter unfamiliar fields or culture-related content, teachers who teach Chinese may need to use a mixture of Chinese and English to teach. High-level classes generally use Chinese in the classroom. 


\subsection{Instruments}

\subsubsection{Questionnaires}

Questionnaire one and two, respectively is about intercultural sensitivity and cultural adaptation questionnaire in English, adopted Chen and Starosta's design of Intercultural Sensitivity Scale (ISS). This scale was validated by Fritz \& Molenberg's confirmatory factor analysis, and its validity and reliability have reached a relatively ideal level. It is also one of the most practical test tools among the current intercultural sensitivity researches.

Intercultural sensitivity, regarded as an independent concept, is a positive attitude to adapt to, understand and appreciate cultural diversity in promoting appropriate and effective cross-cultural communication (Chen \& Starosta, 2000), and is a positive motivation to understand and accept cultural differences. This positive motivation equals as the positive emotional capacity, which combines the cognitive dimension of understanding with the behavioral dimension of operation. Positive affective capacity should be understood in terms of six factors that represent intercultural sensitivity: self-esteem, self-monitoring, open-mindedness, empathy, interaction involvement and non-judgment (Chen \& StaRosta, 2000).

As the research objects are foreign students, including some foreign Chinese, the author bases the original English version of ISS and the Chinese version of Professor Peng on the questionnaire, and students can choose the Chinese or English questionnaire by themselves. Furthermore, the research object was junior high school students, so the author didn't take the original version of ISS, but chose to modify many of the words so that they could be recognized and understood by younger students. In addition, the author added three questions about personal motivation to the authoritative intercultural sensitivity scale, which the author thinks are very important for the study on intercultural sensitivity and intercultural communication of junior high school students. The questionnaire sets 12 open-ended questions in the personal information section, including the most basic personal information, parents' occupation, reason for coming to China, living experience abroad, assessment of their Chinese language ability and understanding of Chinese culture, and channels to understand Chinese culture. There are 35 closed questions in the scale, which can reflect the intercultural sensitivity level of the subjects. Participants were asked to choose between numbers 1-5: 1 means strongly disagree, 2 means disagree, 3 means not sure, 4 means agree, and 5 means strongly agree. See Table 1 for the variable settings of intercultural sensitivity and cultural adaptation scale.

Table 1. Variable Settings of Intercultural Sensitivity and Cultural Adaptation Scale

\begin{tabular}{ll}
\hline Variables & Options \\
\hline Interaction Engagement & $1,7,13,21,22,23,25,28 ;$ \\
Respect for Cultural Difference & $2,3,9,11,16,18,20,33 ;$ \\
Interaction Confidence & $4,5,6,27,32,35 ;$ \\
Interaction Enjoyment & $8,10,12,15,24,26,34 ;$ \\
Interaction Attentiveness & $14,17,19 ;$ \\
Personal Motivation & $29,30,31 ;$
\end{tabular}

A total of 89 questionnaires on intercultural sensitivity and cultural adaptation scale were issued and 80 were recalled, of which 75 were valid.

\subsubsection{Interview}

The individual interviewees in this study are teachers who teach Chinese in the primary school of an international School in Nanchang, which mainly focus on teaching strategies to improve intercultural sensitivity. There are six questions in the outline, and each teacher answers them according to his/her own situation. The unstructured interview method will be adopted in the interview, hoping to make the subjects respond and answer objectively and freely in a comfortable environment.

\subsection{Data Analysis}

Before data analysis, the data obtained from students' questionnaires were compiled in sequence and were input. Then, the reverse score of 15 reverse questions in the scale was converted into data. After that, SPSS22.0 was used for data analysis. First, the arithmetic mean value of six factors was calculated, and the overall analysis of the mean value was conducted to obtain the overall situation of intercultural sensitivity of foreign junior high school students in China. Second, the correlation analysis of various factors within intercultural sensitivity was conducted. In addition to quantitative analysis, the author also combined his own understanding and thinking. 
Classification method will be used to analyze the data of indefinite multiple-choice questions in teachers' questionnaires of intercultural teaching strategies, and then the percentage of total items in each related category will be counted for analysis. To interview five teachers, the author used individual and unstructured interview method. Recordings were made using Total Recorder, and finally text analysis was performed.

\section{Results and Discussion of the Research}

In order to get answers to the two research questions, SPSS22.0 was used to analyze the research data. Through analyzing the mean and standard deviation of each factor of intercultural sensitivity of 89 junior high school students, it was found that the overall level of intercultural sensitivity of foreign junior high school students in this international school is relatively high. According to Pearson correlation analysis, the author found that there is a relatively close relationship between the six factors. Classification method is used to make statistics on the data of indefinite multiple-choice questions in the intercultural teaching strategy questionnaire, and then the percentage of total items in each related category is counted and analyzed at last. The author also made a textual analysis of the intercultural teaching interviews.

\subsection{The Analysis of Overall Intercultural Sensitivity of Junior High School Students}

First, the mean and standard deviation of the six factors of intercultural sensitivity of 89 students were analyzed, and the data in Table 2 were obtained.

Table 2. The Descriptive Statistics of Overall Intercultural Sensitivity of Junior High School Students

\begin{tabular}{lllllll}
\hline & N & Min & Max & Mean & Std. Deviation & Variance \\
\hline Interaction Engagement & 88 & 1.63 & 4.5 & 2.9006 & 0.56387 & 0.318 \\
Respect for Cultural Difference & 88 & 1.43 & 3.86 & 2.5032 & 0.67598 & 0.457 \\
Interaction Confidence & 88 & 1.4 & 5 & 3.2182 & 0.86656 & 0.751 \\
Interaction Enjoyment & 88 & 1 & 4.25 & 2.733 & 0.69563 & 0.484 \\
Interaction Attentiveness & 88 & 0.67 & 4.33 & 2.5076 & 0.71112 & 0.506 \\
Personal Motivation & 88 & 1.63 & 4.63 & 3.0952 & 0.63483 & 0.403 \\
\hline
\end{tabular}

As can be seen from Table 2, the result of intercultural sensitivity of junior high school students is generally in the medium level. According to the mean data, junior high school students have the highest level of interaction confidence, followed by personal motivation, interaction engagement, interaction enjoyment, interaction attentiveness and lastly, respect for cultural difference.

Foreign junior high school students under study show the highest level of confidence in communication, which can't be denied that this is related to their self-confidence. Compared with the conservative and modest style of study in China, foreign junior high school students always have higher self-evaluation and are good at showing their own talents.

\subsection{Correlation Analysis of Various Factors of Intercultural Sensitivity}

In order to understand the relationship between various factors of intercultural sensitivity, the author conducted Pearson correlation analysis with SPSS22.0, and the results are shown in Table 3. 
Table 3. Correlation Analysis of Factors of Intercultural Sensitivity

\begin{tabular}{|c|c|c|c|c|c|c|c|c|}
\hline & & Interaction & Respect & for & Interaction & Interaction & Interaction & Personal \\
\hline & & Engagement & Cultural & Difference & Confidence & Enjoyment & Attentiveness & Motivation \\
\hline Interaction & Pearson & 1 & $.450 * *$ & & $.604 * *$ & $.514 * *$ & $.428 * *$ & $.636^{* *}$ \\
\hline \multirow[t]{3}{*}{ Engagement } & Correlation & & & & & & & \\
\hline & Sig. & & 0 & 0 & & 0 & 0 & 0 \\
\hline & $\mathrm{N}$ & 88 & 88 & 88 & & 88 & 88 & 88 \\
\hline Respect for & Pearson & $.450 * *$ & 1 & & $.446^{* *}$ & $.647 * *$ & $.403 * *$ & $.481 * *$ \\
\hline Cultural & Correlation & & & & & & & \\
\hline \multirow[t]{2}{*}{ Difference } & Sig. & 0 & & 0 & & 0 & 0 & 0 \\
\hline & $\mathrm{N}$ & 88 & 88 & 88 & & 88 & 88 & 88 \\
\hline Interaction & Pearson & $.604 * *$ & $.446^{*}$ & & 1 & $.508 * *$ & 0.205 & $.601 * *$ \\
\hline \multirow[t]{3}{*}{ Confidence } & Correlation & & & & & & & \\
\hline & Sig. & 0 & 0 & & & 0 & 0.055 & 0 \\
\hline & $\mathrm{N}$ & 88 & 88 & 88 & & 88 & 88 & 88 \\
\hline Interaction & Pearson & $.514 * *$ & $.647 * *$ & & $.508 * *$ & 1 & $.457 * *$ & $.507 * *$ \\
\hline \multirow[t]{3}{*}{ Enjoyment } & Correlation & & & & & & & \\
\hline & Sig. & 0 & 0 & 0 & & & 0 & 0 \\
\hline & $\mathrm{N}$ & 88 & 88 & 88 & & 88 & 88 & 88 \\
\hline Interaction & Pearson & $.428 * *$ & $.403 * *$ & & 0.205 & $.457 * *$ & 1 & $.334 * *$ \\
\hline \multirow[t]{3}{*}{ Attentiveness } & Correlation & & & & & & & \\
\hline & Sig. & 0 & 0 & 0.055 & & 0 & & 0.001 \\
\hline & $\mathrm{N}$ & 88 & 88 & 88 & & 88 & 88 & 88 \\
\hline Personal & Pearson & $.636^{* *}$ & $.481 * *$ & & $.601 * *$ & $.507 * *$ & $.334 * *$ & 1 \\
\hline \multirow[t]{3}{*}{ Motivation } & Correlation & & & & & & & \\
\hline & Sig. & 0 & 0 & 0 & & 0 & 0.001 & \\
\hline & $\mathrm{N}$ & 88 & 88 & 88 & & 88 & 88 & 88 \\
\hline
\end{tabular}

Sample correlation coefficient reflects the strength of the linear correlation between two variables, for different types of variables should be taken to the correlation of different indexes, but their range is the same, that is between- 1 and $+1, r>0$ means exists positive correlation between two variables; $r<0$ means two variables are negative correlation; $r=1$ shows two variables exist completely positive correlation; $r=-1$ indicates that there is a completely negative correlation between the two variables; $r=0$ indicates that there is no linear correlation between the two variables. $|\mathrm{r}|>0.8$ indicates that there is a strong linear correlation between the two variables, and $|\mathrm{r}|<0.3$ indicates that there is a weak linear correlation between the two variables.

Table 3 shows the correlation of six factors of intercultural sensitivity. $\mathrm{P}=0.055>\mathrm{a}=0.05$ shows no significant correlation between interaction confidence and interaction attentiveness, while $\mathrm{P}$ values of all other factors are less than 0.05 . Therefore, all other factors are significantly positively correlated.

Among the six factors, the strongest correlation is respect for cultural difference and interaction enjoyment, with a correlation coefficient of 0.647 , reaching a moderate correlation. That is to say, students with strong sense of identity of respect for cultural difference are more likely to get a sense of pleasure in intercultural communication, enjoy the process of cultural differences and exchange of knowledge and information. The sense of pleasure is enhanced in the process of communication, and the communicative confidence will improve as well.

Secondly, the correlation coefficient between interaction engagement and personal motivation is 0.636 , and that between interaction engagement and interaction confidence is 0.604 , showing a relatively moderate correlation. These data indicate that the stronger the personal motivation of students, the more willing they are to participate in interaction activities. With the deepening of participation, their understanding and experience of cultural 
differences will also deepen. The correlation between interaction engagement and interaction confidence is also obvious, indicating that confident students will participate in communication activities more actively.

Finally, the correlation coefficient between interaction confidence and interaction attentiveness only remains 0.205 with a rather low significant correlation, showing that concentration in the process of communication doesn't help improve communicative confidence. Students who focus on the communicative process may just intend to cooperate with the teacher and classmates to complete the activities in the classroom, which doesn't mean that they are confident to complete these activities well.

\subsection{Analysis of Intercultural Teaching Strategy Interview}

The author interviewed the teachers' using of teaching strategies related to intercultural sensitivity in the classroom and then collated the results

When asked how to balance the language content, cultural teaching and students' personal situation in the teaching materials in lesson preparation, four out of five teachers think that the teaching materials should be the main part, and the cultural content related to the unit theme should be interspersed in time. Cultural teaching and evaluation should be based on the age of students, personality and other specific circumstances to adopt a specific way. But one teacher thinks international schools should move beyond textbooks and rearrange the content around cultural themes.

The second question: what do you know about intercultural sensitivity? The five teachers were able to blurt out some aspects of intercultural sensitivity, but they were a little narrow, especially the attribution of communicative concentration and confidence was not enough.

The third question: how to evaluate students' intercultural sensitivity and intercultural communication ability? The five teachers all said that they learned about it mainly through classroom, observation after class and feedback from parents.

The fourth question: What kinds of teaching strategies are often used in class to improve students' intercultural sensitivity? The emphasis of each teacher's answer varies. Some teachers answered that they should learn more Chinese local culture and experience more. Other teachers suggested that students shouldn't only understand the host Chinese culture, but also the cultures of other students. Most of the teachers listed specific teaching strategies and methods, such as setting up cultural programs, holding festival cultural activities and encouraging students to communicate with local people.

The fifth question: When reflecting on own teaching with the view to improving intercultural sensitivity, what aspects need to be improved or made more efforts? All the teachers expressed their willingness to read more, learn more about intercultural sensitivity, and to improve their research and professional level. Three teachers hoped to have the opportunity to learn from and observe each other internally.

In general, most teachers pay more attention to the textbooks themselves when preparing lessons, and use specific teaching strategies to cultivate students' intercultural awareness in the classroom. Although their understanding of intercultural sensitivity is a little narrow, they are willing to learn more about this concept and improve their professional levels.

\subsection{Suggestions on Intercultural Teaching Strategies}

\subsubsection{Reading and Writing Strategy}

Reading is an important method for people to obtain information and learn other cultures, as well as one of the main tasks of learning other languages. Reading teaching strategies that focus on improving intercultural sensitivity require teachers to do more targeted preparations.

First, make sure that the materials chosen include certain cultural points, which will help students understand the geography, history, or politics of other cultural traditions which are different from their own culture.

Second, choosing different reading materials for students with different English levels. When guiding the reading of literary works, newspapers or magazines, teachers need to accumulate content related to cultural background, social customs, and social relations, and then explain and clarify them clearly.

Thirdly, adopt different reading methods and then design colorful reading activities.

Taking the author's personal teaching experience as an example, the reading class of junior high school students adopts collective reading, and the teacher will select some reading materials related to the teaching content and themes. Most of the reading materials are basically equipped with vivid pictures to facilitate students to "read" it; and for junior high school students who have studied English for more than three years, the teacher can give a 
range of reading materials for them to choose. Sorting is also an essential learning skill, which requires students to have discriminating abilities. Students can choose to read with peers, read independently, and develop the habit of recording learning journal. The journal can improve gradually from a few sentences to the complete paragraphs and compositions. Later, reading activities should be more colorful, such as continuation, rewriting, role play or debate.

\subsubsection{Evaluation Strategy}

Evaluation, an integral part of teaching and learning, which involves analyzing student performance and providing useful information for teaching practice. It can also determine what students know, understand and feel at different learning stages. Portfolio is often used to record the growth of students' abilities, knowledge, and cultural emotions. Teachers should actively participate in the assessment of students' learning progress and take this as part of their efforts to cultivate students' critical thinking and self-assessment skills.

Evaluations that focus on improving intercultural sensitivity can take different forms, such as creating a series of propositions that design cultural conflicts, thus students can choose their own presentation methods such as skits, sketches, discussions, PPT, and posters. When teaching the "Clothing and Dressing", in addition to learning sentences about inquiries, answers, and descriptions of dressing, students are also introduced to clothes with typical foreign characteristics. For instance, a certain group chose to use cardboard, crepe paper, newspaper, cardboard, ribbons and other materials to simply make Victorian women's clothing. Therefore, the final evaluation method they chose was clothing display and detail elaboration. Even in the assessment of language classes, teachers can make appropriate feedback and assessments by observing students' cultural participation, integration, and attitudes and behaviors when dealing with cultural conflicts.

\subsubsection{Activity Strategy}

Long-lasting activities that emphasize theoretical knowledge, such as lectures and reports, are not suitable for junior high school students, because the acquisition of perceptual experience of junior high school students is more rewarding than the theoretical knowledge. Therefore, students are encouraged to actively explore cultural differences between China and foreign countries under the premise of certain tasks, which inspires them to learn cooperatively, collaboratively and inquiringly.

Students have different cognitive styles, some are field-independent style, and others are field-dependent characteristics. In this case, teachers can group students with different or similar learning levels or styles together to help them choose different methods to complete the tasks.

Electronic products are very popular among young people in the 21 st century, and teachers can use multimedia technologies such as TV, movies, tablets, and computers. These technologies can intuitively create cultural situations and enable students to quickly enter the role of cultural background. Organizing debates, competitions, and performances of various specifications can also improve students' participation, concentration and confidence.

\section{Conclusions}

How to improve the intercultural sensitivity and enhance language ability and skills by increasing this sensitivity, and then ultimately achieve the goal of cultivating a humanistic feeling and a global perspective, which depends on the learning strategies of the learners and the teaching choices of the teacher. For young communicators, the teacher's teaching strategy is even more important. Scientific and effective teaching strategies help communicators to maintain their mother tongue and its cultural identity while acquiring other languages. Specifically, through effective and specific language and intercultural teaching strategies, students can not only feel the charm of other languages and cultures, but also better understand the culture of their mother tongue, and even unconsciously compare their native culture with other cultures, analyze their differences and similarities from an objective, historical, and materialistic perspective. Based on junior high school students' different cognitive characteristics and preferences, specific teaching methods are selected to attract their interest in intercultural learning. At the same time, expanding intercultural teaching resources, especially network resources, and activating parents' participation will make students' intercultural learning more effective.

First, the research object is limited to junior middle school students and teachers, which is not representative enough. In addition, students will unconsciously overestimate themselves when filling in the Intercultural Sensitivity and Adaptation Scale, or their filling is still a little different from their daily performance. Even teachers tend to overestimate themselves when doing Strategies of Intercultural Teaching (Teachers' Survey). It is hoped that future research on intercultural sensitivity and teaching strategies can select more research objects 
comprehensively. The observation of intercultural communication and classroom teaching can be supplemented to determine the level of intercultural sensitivity and the use of teaching strategies

\section{References}

Ali, A. P. (2015). Intercultural sensitivity: An empirical study of Iranian EFL learners. International Journal of English Language Education, 3(2), 1-13. https://doi.org/10.5296/ijele.v3i2.7474

Bennett, M. J. (1986). A Developmental Approach to Training Intercultural Sensitivity. International Journal of Intercultural Relations, 10(2), 179-186. https://doi.org/10.1016/0147-1767(86)90005-2

Bennett, M. J. (1993). Towards Ethnorelativism: A Developmental Model of Intercultural Sensitivity. In R. M. Paige (Ed.), Education for the Intercultural experience. Yarmouth, ME: Intercultural Press.

Bennett, M. J. (1999). Developing Intercultural Competence in the Language Classroom. In R. M. Paige (Ed.), Culturae as the Core: Integrating Culture into the Language Curriculum. Minnesota: The Regent of the University of Minnesota.

Bhawuk, D. P. S., \& Brislin, R. (1992). The Measurement of Intercultural Sensitivity Using the Concepts of Individualism and Collectivism. International Journal of Intercultural Relations, (16), 423-436. https://doi.org/10.1016/0147-1767(92)90031-O

Brislin, R. W. (1983). Cross-Cultural Research in Psychology. Annual Review of Psychology, 34, 363-400. https://doi.org/10.1146/annurev.ps.34.020183.002051

Bronfenbrenner, U., Harding, J., \& Gallwey, M. (1958). The Development and Validation of a Scale to Measure Affective Sensitivity (Empathy). Journal of Counseling Psychology, 18, 407-412. https://doi.org/10.1037/h0031492

Chen, G. M., \& Starosta, W. J. (2000). The Development and Validation of the Intercultural Communication Sensitivity Scale. Human Communication, 3, 1-15.

Fritz, W., Mollenberg, A., \& Chen, G. M. (2002). Measuring Intercultural Sensitivity in Different Cultural Context. Intercultural Communication Studies, (11), 165-176.

Hall, E. T. (1976). Beyond Culture. Garden City, New York: Anchor Press.

Hammer, M. R. (1998). A Measure of Intercultural Sensitivity: The Intercultural Development Inventory. In S. Fowler \& M. Fowler (Eds.), The Intercultural Sourcebook Volume 2. Yarmouth, ME: Intercultural Press.

Kim, Y. Y. (2005). Adapting to a New Culture: An Integrative Communication Theory. In William B. Gudykunst (Ed.), Theorizing about Intercultural Communication. Thousand Oaks, CA: Sage.

Kolb, D. (1984). Experiential Learning: experience as the source of learning and development. Prentice-Hall.

Loo, R. A. (1999). Structural and Cross-cultural Evaluation of the Inventory of Cross-cultural Sensitivity. Journal of Social Behavior \& Personality, 14(2), 267-278.

Martinsen, R. (2011). Predicting Changes in Cultural Sensitivity among Students of Spanish During Short-term Study Abroad. Hispania, 94(1), 121-141.

McClelland, D. C. (1973). Testing for Competence Rather Than for "Intelligence". American Psychologist, 28(1), $1-14$.

Ruben, B. D. (1976). Assessing Communication Competency for Intercultural Adaptation. Group and Organizational Studies, 1(3), 334-354. https://doi.org/10.1177/105960117600100308

Ruben, B. D., \& Kealey, D. J. (1979). Behavioral assessment of communication competency and the prediction of cross-cultural adaptation. International Journal of intercultural Relations, 3, 1547. https://doi.org/10.1016/0147-1767(79)90045-2

Ruben, B. D. (1989). The Study of Cross-Cultural Competence: Traditions and Contemporary Issue. International Journal of Intercultural Relations, 13(3), 229-240. https://doi.org/10.1016/0147-1767(89)90011-4

Sakurauchi, Y. H. (2014). Teaching and Learning for Intercultural Sensitivity: A Cross-Cultural Examination of American Domestic Students and Japanese Exchange Students. Dissertations and Theses. Paper 1643.

Spitzberg, B. (1994). A Model of Intercultural Communication Competence. In Samovar, L. \& Porter (Eds.), Intercultural Communication: A reader (pp. 347-359). Belmont, CA: Wadsworth. 
Straffon, D. A. (2003). Assessing the Intercultural Sensitivity of High School Students Attending an Intercultural School. International Journal of Intercultural Relations, 27(4), 487-501. https://doi.org/10.1016/S0147-1767(03)00035-X

$\mathrm{Yu}$, W. (2012). An Empirical Research on Foreign Learners' Intercultural Competence: Sensitivity and Effectiveness. Chinese Teaching in the World, (4), 551-560.

\section{Copyrights}

Copyright for this article is retained by the author(s), with first publication rights granted to the journal.

This is an open-access article distributed under the terms and conditions of the Creative Commons Attribution license (http://creativecommons.org/licenses/by/4.0/). 